Article

\title{
Optimization on Reducing Slag Entrapment in $150 \times$ 1270 mm Slab Continuous Casting Mold
}

\author{
Yang Wang ${ }^{1}$, Shufeng Yang ${ }^{1, *}$, Feng Wang ${ }^{2}$ and Jingshe $\mathrm{Li}^{1}$ \\ 1 School of Metallurgical and Ecological Engineering, University of Science and Technology Beijing, \\ Beijing 100083, China; ustb_wang@163.com (Y.W.); lijingshe@ustb.edu.cn (J.L.) \\ 2 Institute of Engineering Technology, University of Science and Technology Beijing, Beijing 100083, China; \\ wangfeng02@hbisco.com \\ * Correspondence: yangshufeng@ustb.edu.cn; Tel.: +86-010-62334277
}

Received: 7 May 2019; Accepted: 23 May 2019; Published: 31 May 2019

check for updates

\begin{abstract}
To reduce slag entrapment in $150 \times 1270 \mathrm{~mm}$ slab continuous casting molds at the Tang Steel Company, the effect of submerged entrance nozzle (SEN) depth and casting speed on the phenomenon was studied by computational fluid dynamics simulations. Then, the slag entrapment behavior in continuous casting molds, utilizing Large Eddy Simulation (LES) by coupling the volume of fluid (VOF) method, was also used. Finally, the effect of several common oils usually used to simulate slag in water modelling on slag entrapment was discussed and the water modelling results were used to validate the numerical simulation findings. The results showed that the optimum scheme is a submerged depth of SEN $90 \mathrm{~mm}$ and a casting speed of $1.6 \mathrm{~m} / \mathrm{min}$. Under optimal conditions, the maximum surface velocity is smallest $(0.335 \mathrm{~m} / \mathrm{s})$ and the maximum slag entrapment ratio $(0.44 \%)$ appears in the position of $0.1 \mathrm{~m}$ below the meniscus after $15 \mathrm{~s}$. The water modelling results were in good agreement with the numerical simulation results.
\end{abstract}

Keywords: continuous casting; mold; slag entrapment; numerical modelling; process simulations; fluid dynamics

\section{Introduction}

The core concept of high efficiency continuous casting is to produce high quality defect-free steel at high casting speeds. At high casting speeds, slag entrapment in molds seriously deteriorate the quality of steel products, becoming one of the main obstacles affecting the production of high value-added steel products [1].

Numerous researchers [2-7] have studied slag entrapment in the mold region of the continuous casting process using water modelling. Thomas et al. [8] have summarized that mold slag entrainment could cause both surface and internal defects in final products if the entrained droplets become trapped in the solidifying metal, which makes it a significant problem in the production of clean steel. Further analysis indicates three kinds of mold slag entrapment mechanisms: Vortexing, shear force, and turbulence at the meniscus. Iguchi et al. [9] focused on the shear flow instability between molten steel flow and mold powder as one of causes for mold powder entrapment, and investigated the effect of kinematic viscosity of mold powder on the onset of entrapment. However, they did not explain why they chose salt water, which has a different density ratio to water. However, the role of the steel-slag interface has only seen minimal investigation. When a liquid-liquid interface is exposed to a shear force from a flow initiated by a rotating roller, the meniscus is deformed. The flow acts tangentially on the interface leading to the formation of a finger-like protrusion, as shown in Figure 1. The interfacial tension acts against the tendency for droplet entrainment. In order to describe the flow-induced 
entrainment of lighter phase droplets, dimensionless relations are derived. The critical flow velocity (u) for entrainment is an important parameter for slag entrapment in continuous casting molds.

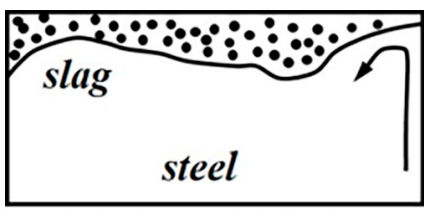

(a)

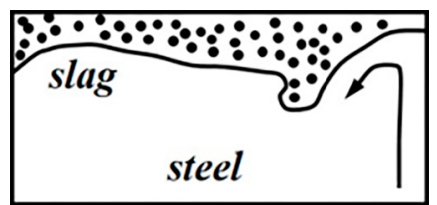

(b)

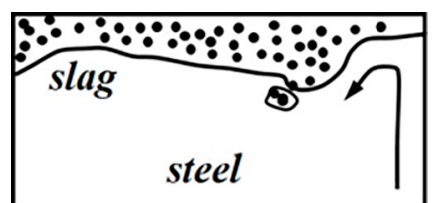

(c)

Figure 1. Slag entrapment by shear-layer instability: (a) flow upward after stream striking narrow face, (b) shearing effect on slag layer, (c) formation of slag droplet.

Thomas et al. [8] mentioned that the interface between two density-stratified fluids with relative motion will become unstable with a sufficiently large difference in velocity. Most studies of slag entrainment have identified this phenomenon, known as Kelvin-Helmholtz instability (KHI), as a cause of mold slag entrainment, as shown in Figure 1. This shear instability mechanism is most likely to occur halfway between the narrow face and the submerged entrance nozzle (SEN), where the horizontal surface velocity is largest. Helmholtz first explored the theoretical condition for the instability [10], and an alternative prediction [11] of the Kelvin-Helmholtz instability for finite layer thickness, inviscid fluids and zero interfacial tension gives a critical velocity at the same time. Jari et al. [12] obtained a modified Weber number through experimentation. The modified Weber number could be used as a criterion for droplet formation from the oil layer. However, it does not include oil viscosity, which makes it insufficient criterion for slag entrainment.

Another important dimensionless quantity in slag entrapment is the capillary number, which is defined by the ratio of deforming stress exerted by a continuous liquid and the counteracting Laplace pressure $[13,14]$. However, there are no comprehensive similarity criteria with regards to what kind of oil should be used in a water model to properly represent the slag entrapment occurring in a continuous casting mold. The influence of the density ratio on critical velocity was noted in a previous study where the values of critical velocity obtained were assumed without justification to be smaller than in a real steel-slag system $[3,15]$.

In actual production, SEN depth and casting speed in continuous casting process are two direct impact factors on the shear-layer instability and further affect the occurrence of slag entrapment. To reduce the slag entrapment in a $150 \times 1270 \mathrm{~mm}$ slab continuous casting mold at the Tang Steel Company, in this paper, the optimum submerged depth of SEN and casting speed were studied using numerical simulations. Then, slag entrapment in the mold using computational fluid dynamics simulations, utilizing the LES (Large Eddy Simulation) coupling volume of fluid (VOF) method, was also used. Finally, the effect of several common oils usually used to simulate slag in water modelling on slag entrapment was discussed and the water modelling results were used to validate the numerical simulation findings.

\section{Experimental Section}

\subsection{Experimental Setup}

Figure 2 shows a schematic of the full-scale water modelling experimental apparatus, consisting of mold with a submerged nozzle, water tank, electronic flowmeter, pump and high-speed camera.

The bottom of the mold was connected to the water tank on the top through water pipes. After flowing out of the outlet, water was pumped back to the top tank. A high-speed camera in front of the zone, shown as a red dotted line, was used to record fluctuations of the water-oil interface and the entrapment of oil droplets. For each experimental work with the water-oil system, both liquids were renewed. 


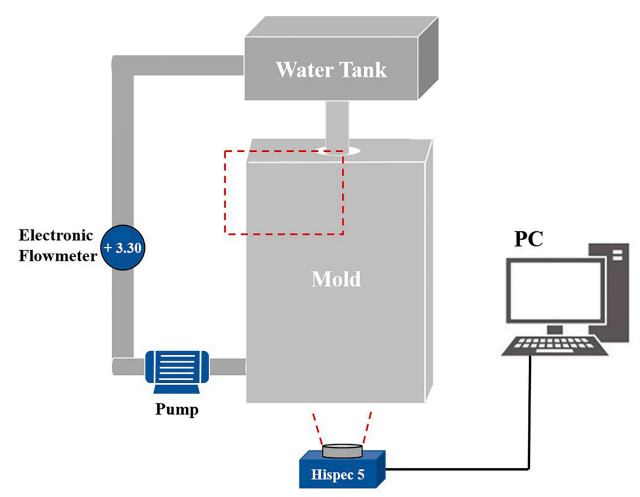

Figure 2. Schematic drawing of the experimental apparatus.

The mold geometry is shown in Figure 3a. A straight-mold steel caster of a 150-mm-thick and 1270-mm-wide strand is modeled with a water model that is $1100 \mathrm{~mm}$ in length. The example submerged entrance nozzle configuration is also shown in Figure 3b.

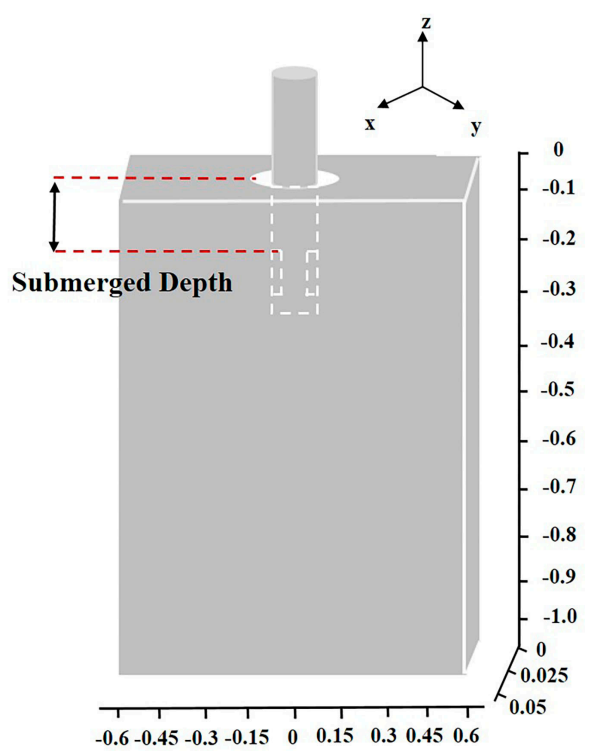

(a)
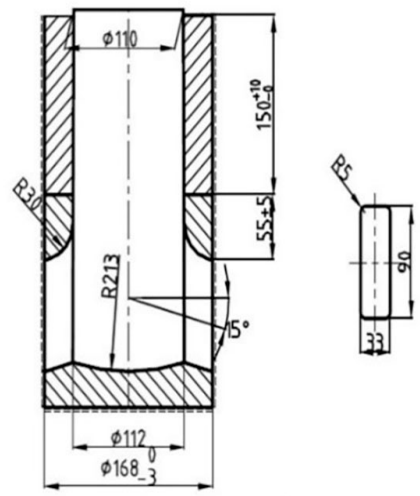

(b)

Figure 3. Schematic of mold water model: (a) mold size and (b) submerged entrance nozzle size.

\subsection{Similarity Criterion and Dimensional Analysis}

The critical flow velocity $U^{*}$ for slag entrapment is a function of the material properties of both phases:

$$
U^{*}=f\left\{\rho_{1}, \rho_{2}, \eta_{1}, \eta_{2}, \delta, g\right\}
$$

where $\eta_{1}$ and $\eta_{2}$ are the viscosities (Pa.s), $\rho_{1}$ and $\rho_{2}$ are the densities of the lighter and heavier phases in contact $\left(\mathrm{kg} / \mathrm{m}^{3}\right)$. $\mathrm{g}$ is the acceleration of gravity $\left(\mathrm{m} / \mathrm{s}^{2}\right)$ and $\delta$ is the interface tension force $(\mathrm{N} / \mathrm{m})$.

According to the Buckingham $\pi$ theorem, it is possible to achieve four $\pi$ groups:

$$
\pi_{1}=f\left\{\pi_{2}, \pi_{3}, \pi_{4}\right\}
$$

Selecting $\eta_{2}, \rho_{2}$, and $u$ as basic quantities, the following could be obtained:

$$
\begin{aligned}
{\left[\eta_{2}\right] } & =\left[M^{1}, L^{-1}, T^{-1}\right] \\
{[u] } & =\left[M^{0}, L^{1}, T^{-1}\right] \\
{\left[\rho_{2}\right] } & =\left[M^{1}, L^{0}, T^{-2}\right]
\end{aligned}
$$


Then,

$$
\left|\begin{array}{ccc}
1 & -1 & -1 \\
0 & 1 & -1 \\
1 & -3 & 0
\end{array}\right| \neq 0
$$

By solving the above equation, then $\pi_{1}=\delta / u \eta 2, \pi 1=g \eta_{2} / u \rho_{2}$, could be obtained by the derivation.

$$
\frac{1}{\pi_{1}}=\frac{u \eta_{2}}{\delta}=C a
$$

The reciprocal of $\pi_{1}$ is the ratio of the deforming stress exerted by the heavier phase and the counteracting Laplace pressure, and it is called the capillary number (Ca) [16-22].

At the same time:

$$
\frac{1}{\pi_{2}}=\frac{u^{3} \rho}{g \eta}=\frac{u^{2} \rho u l}{g l \eta}=F r \cdot R e
$$

The dimensionless Froude number $(F r)$ represents the ratio of momentum to buoyancy force. The Reynolds number $(R e)$ is the ratio of inertia and viscous force.

$$
\begin{aligned}
& \pi_{3}=\rho_{1} / \rho_{2} \\
& \pi_{4}=\eta_{1} / \eta_{2}
\end{aligned}
$$

As such, the general relation below can be expressed from the above equations:

$$
C a=f\left(F r \cdot \operatorname{Re}, \frac{\rho_{1}}{\rho_{2}}, \frac{\eta_{1}}{\eta_{2}}\right)
$$

Finally, by observation, the capillary number can be written as the ratio of the Weber number to the Reynolds number, as shown below:

$$
C a=\frac{u \eta}{\delta}=\frac{\rho u^{2} l}{\delta} \cdot \frac{\eta}{\rho u l}=W e / R e
$$

The Weber number represents the ratio of the momentum to interfacial tension force. Thus, the design of a water modelling experiment should make all the parameters (such as $W e, F r, R e, \rho_{1} / \rho_{2}$, $\eta_{1} / \eta_{2}$ ) similar simultaneously to properly simulate the steelmaking mold via water modelling.

For the high-velocity flow conditions present in a steel continuous caster, fully developed turbulent flow conditions are always produced, so achieving Reynold's similarity by matching the ratio of the momentum and diffusion forces was judged to be less important, as long as fully turbulent flow conditions are maintained [2].

For the $\mathrm{Fr}$ and We similarity, the water model needs to satisfy the following equations:

$$
\begin{gathered}
\frac{u_{\text {steel }}^{2}}{g L_{\text {steel }}}=\frac{u_{\text {water }}^{2}}{g L_{\text {water }}} \\
\frac{u_{\text {steel }}^{2} L_{\text {steel }} \rho_{\text {steel }}}{\delta_{F e-S l a g}}=\frac{u_{\text {water }}^{2} L_{\text {water }} \rho_{\text {water }}}{\delta_{\text {water-oil }}}
\end{gathered}
$$

where $L_{\text {steel }}$ is the actual size, $L_{\text {water }}$ is the characteristic length of water modelling; $\rho_{\text {steel }}$ is the molten steel density $\left(7020 \mathrm{~kg} / \mathrm{m}^{3}\right), \rho_{\text {water }}$ is the water density $\left(998 \mathrm{~kg} / \mathrm{m}^{3}\right)$, and $\delta_{\mathrm{Fe}-\text { Slag }}$ is the surface tension, 
$1.2 \mathrm{~N} / \mathrm{m}$, for molten steel and slag [15], and $\delta_{\text {water-oil }}$ depends on the oil used in the experiment. Applying a general scale factor of $\lambda=L_{\text {steel }} / L_{\text {water }}$ in Equations (11) and (12), the combined scale factor should be:

$$
\lambda=\sqrt{\frac{\rho_{s} \cdot \delta_{w-o}}{\rho_{w} \cdot \delta_{F e-S l a g}}}
$$

In this paper, a scale factor of 0.5 was determined according to the experimental conditions.

\subsection{Experiment Schemes and Materials}

Firstly, four cases, which were calculated using FLUENT, were as follows: A, submerged depth $70 \mathrm{~mm}$, casting speed $1.6 \mathrm{~m} / \mathrm{min}$; B, submerged depth $70 \mathrm{~mm}$, casting speed $1.8 \mathrm{~m} / \mathrm{min}$; C, submerged depth $90 \mathrm{~mm}$, casting speed $1.6 \mathrm{~m} / \mathrm{min}$; D, submerged depth $90 \mathrm{~mm}$, casting speed $1.8 \mathrm{~m} / \mathrm{min}$. Secondly, the best plan was calculated using the LES model with the slag layer. Finally, a water model was carried out and a high-speed camera was used to capture the oil droplet entrapments.

In this paper, water was used as the heavier phase. Silicone oil AK 0.65 was used as the lighter phase to develop a liquid-liquid interface with density $760 \mathrm{~kg} / \mathrm{m}^{3}$ and interface tension $0.04 \mathrm{~N} / \mathrm{m}$, which behaves nearly like a Newtonian liquid.

\subsection{Governing Equations and Boundary Conditions}

The commercial software FLUENT was used to solve the LES model using a DELL 8-core personal computer with $64.0 \mathrm{~GB}$ of random-access memory and a $3.00 \mathrm{GHz}$ Intel $®$ Xeon processor for parallel computing. The volume of fluid (VOF) model was used to track the interface between the phases. In this work, the tracking of the metal/slag interfaces was accomplished by solving a continuity equation for the volume fraction of the steel and slag phases. The LES model was also used to calculate the slag entrapment in the continuous casting mold. The fluid region in the entire mold of the continuous casting process was solved with 500,000 hexahedral structured meshes as shown in Figure 4.

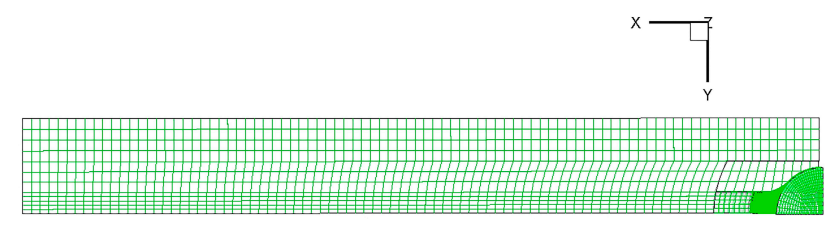

(a)

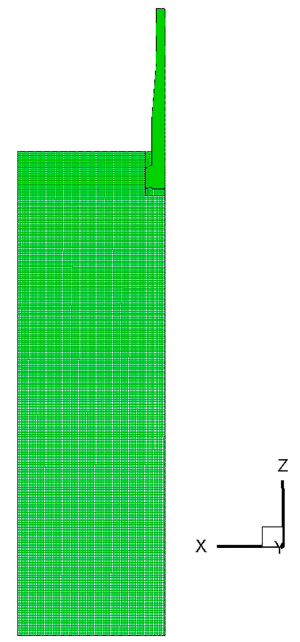

(b)

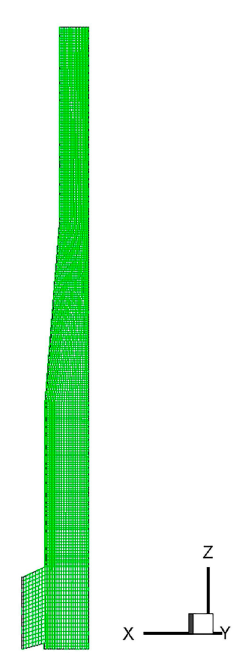

(c)

Figure 4. Schematic of meshes used for numerical simulation: (a) top view; (b) side view; (c) submerged entrance nozzle. 
The time of calculation was $15 \mathrm{~s}$ with a time step of $0.001 \mathrm{~s}$. The finite volume method (FVM) was used to process the discrete data, and the SIMPLEC (Semi-Implicit Method for Pressure Linked Equations-Consistent) algorithm was used to solve the coupled equations of the FVM. The nozzle submergence depth was $90 \mathrm{~mm}$, shown in Figure 3a. According to the casting speed of $1.6 \mathrm{~m} / \mathrm{min}$, the inlet velocity $1.329 \mathrm{~m} / \mathrm{s}$ was back-calculated using continuity. The velocity inlet and pressure outlet were used. Steel/slag interface tension was 1.2 N/M [15].

\section{Results and Discussions}

\subsection{Submerged Depth and Casting Speed}

The velocity magnitude field and vector of each scheme in the wide face of the mold was calculated via computational fluid dynamics (CFD) modelling, as shown in Figure 5.

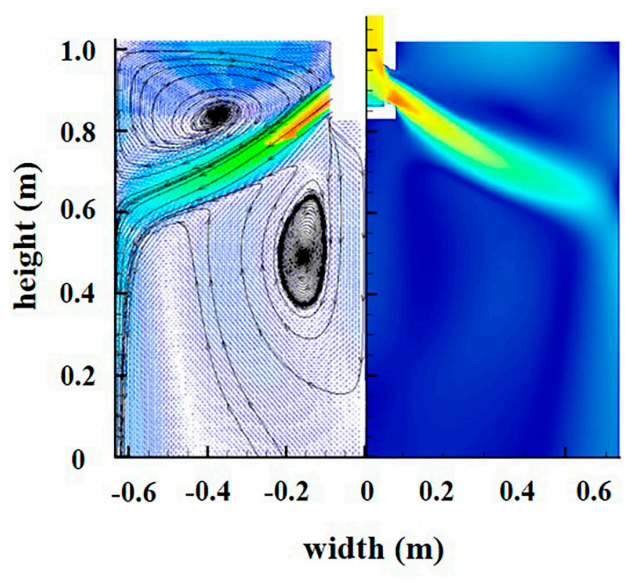

(a)

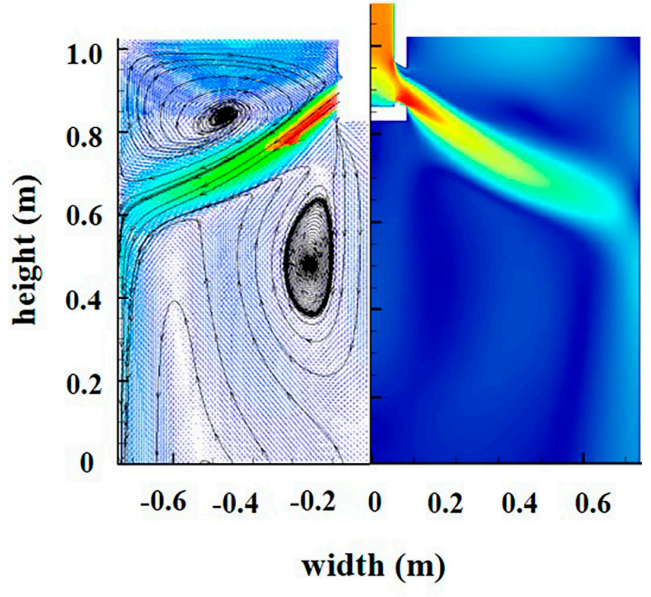

(c)

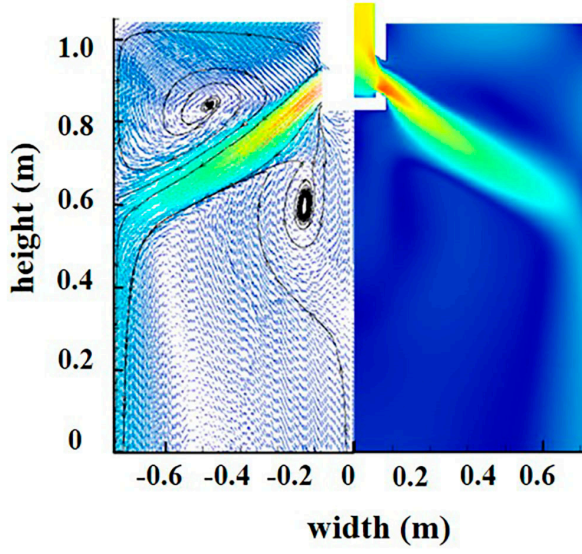

(b)

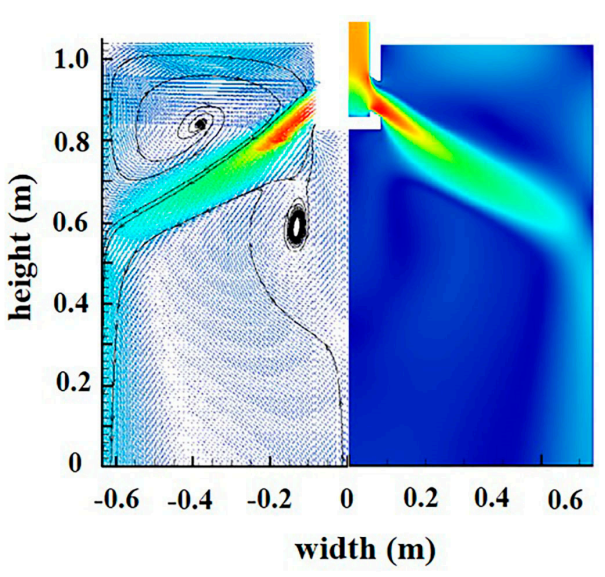

(d)

Figure 5. Contour and vector of velocity at wide face in mold: (a) casting speed $1.6 \mathrm{~m} / \mathrm{min}$, submerged depth $70 \mathrm{~mm}$; (b) casting speed $1.8 \mathrm{~m} / \mathrm{min}$, submerged depth $70 \mathrm{~mm}$; (c) casting speed $1.6 \mathrm{~m} / \mathrm{min}$, submerged depth $90 \mathrm{~mm}$; (d) casting speed $1.8 \mathrm{~m} / \mathrm{min}$, submerged depth $90 \mathrm{~mm}$.

It could be seen that there are two strands of swirling flow in the mold during continuous casting: The upper part and the lower part. For the upper part, the influence of the velocity magnitude on slag entrainment is very important. When the flow rushes out of the nozzle port, it will move forward along the nozzle angle and then impact the narrow face, producing two streams. The upward flow will disturb the molten steel at the free surface, sometimes resulting in slag entrapment. The velocity magnitude field at the free surface is shown in Figure 6. 


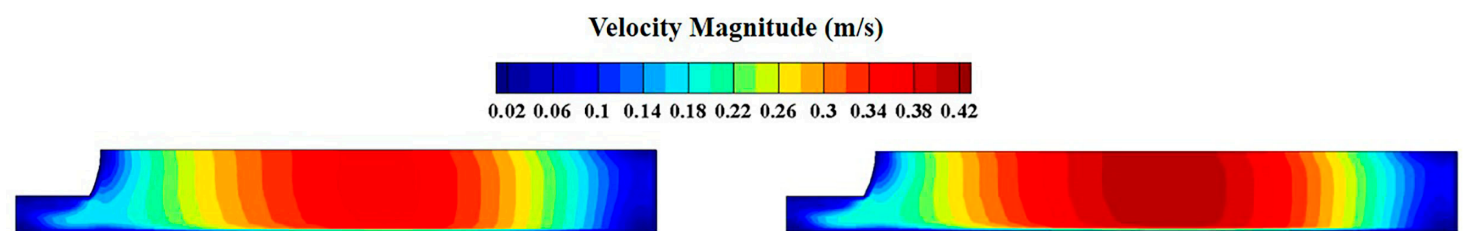

(a)

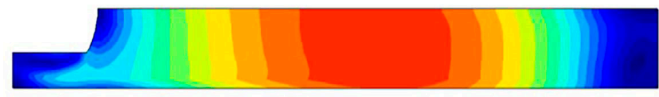

(c) (b)

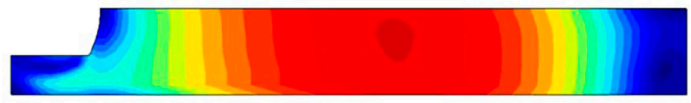

(d)

Figure 6. Contour of velocity magnitude at free-surface: (a) casting speed $1.6 \mathrm{~m} / \mathrm{min}$, submerged depth $70 \mathrm{~mm}$; (b) casting speed $1.8 \mathrm{~m} / \mathrm{min}$, submerged depth $70 \mathrm{~mm}$; (c) casting speed $1.6 \mathrm{~m} / \mathrm{min}$, submerged depth $90 \mathrm{~mm}$; (d) casting speed $1.8 \mathrm{~m} / \mathrm{min}$, submerged depth $90 \mathrm{~mm}$.

It could be seen that the velocity was highest at the mid-section of the free surface. The fluid with a high-speed velocity will impact the interface between molten steel and slag, so the higher the surface speed is, the easier slag entrapment occurs. To further compare the free-surface velocity of the four schemes, the velocity distribution along the central line of the nozzle center at free surface was plotted as Figure 7. Surface velocity reaches maximum when the location is $0.35 \mathrm{~m}$ away from the nozzle center of each scheme. And maximum surface velocity is smallest $(0.335 \mathrm{~m} / \mathrm{s})$ when the submerged depth is $90 \mathrm{~mm}$ and casting speed is $1.6 \mathrm{~m} / \mathrm{min}$ as shown in Table 1 . Compared with the scheme of $70 \mathrm{~mm}$, submerged depth and $1.8 \mathrm{~m} / \mathrm{min}$ casting speed, the maximum surface velocity was reduced by $19.1 \%$ (from $0.414 \mathrm{~m} / \mathrm{s}$ to $0.335 \mathrm{~m} / \mathrm{s}$ ). Even compared with the other two conditions in Table 1, the maximum surface velocity of $90 \mathrm{~mm}$ submerged depth and $1.6 \mathrm{~m} / \mathrm{min}$ casting speed was still reduced by $11.4 \%$ and $8.3 \%$, respectively.

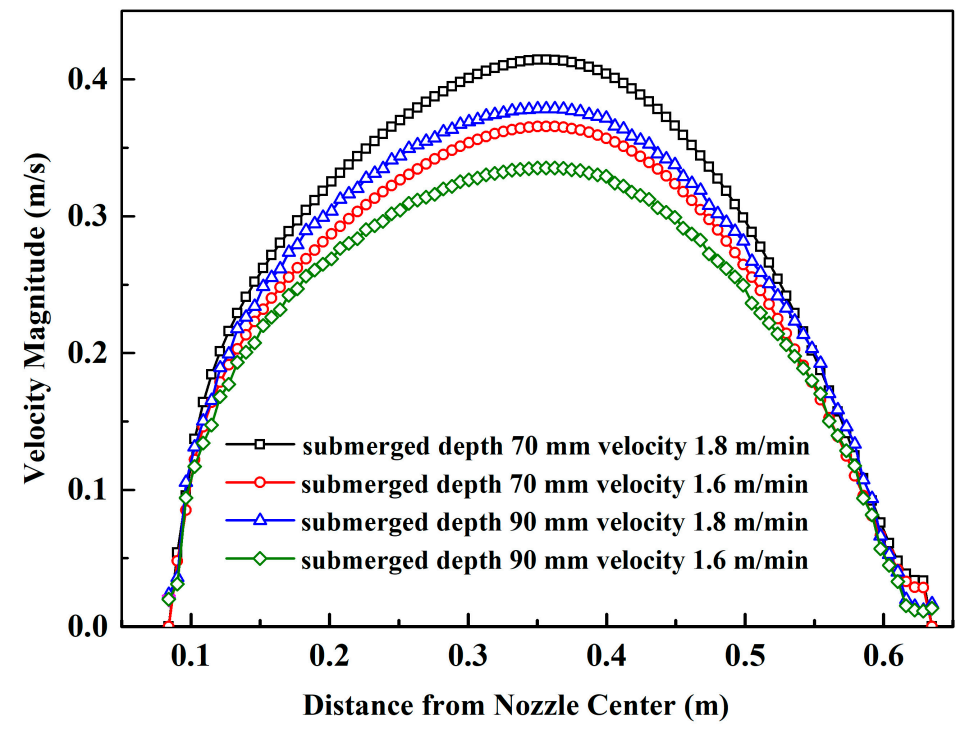

Figure 7. Velocity distribution of free-surface along the central line of the nozzle.

Table 1. Maximum surface velocity of different submerged depth and casting speed $(\mathrm{m} / \mathrm{s})$.

\begin{tabular}{|c|c|c|c|}
\hline $\begin{array}{c}70 \mathrm{~mm} \\
1.8 \mathrm{~m} / \mathrm{min}\end{array}$ & $\begin{array}{c}90 \mathrm{~mm} \\
1.8 \mathrm{~m} / \mathrm{min}\end{array}$ & $\begin{array}{c}70 \mathrm{~mm} \\
1.6 \mathrm{~m} / \mathrm{min}\end{array}$ & $\begin{array}{c}90 \mathrm{~mm} \\
1.6 \mathrm{~m} / \mathrm{min}\end{array}$ \\
\hline 0.414 & 0.379 & 0.366 & 0.335 \\
\hline
\end{tabular}

Thus, the optimum scheme was determined: Submerged depth $90 \mathrm{~mm}$ and casting speed $1.6 \mathrm{~m} / \mathrm{min}$. 


\subsection{Slag Entrapment Ratio (SER)}

Based on the previous section's discussion, we calculated the location of slag droplets at different times to study the behavior of the slag droplets involved in the conditions of submerged depth $90 \mathrm{~mm}$ and casting speed $1.6 \mathrm{~m} / \mathrm{min}$, as shown in Figure 8 . From the results, we could find that the slag entrapment was clearly observed at $t=5 \mathrm{~s}$ due to the impact of the fluid on the steel slag interface. After that, new slag droplets were constantly involved in the molten steel as time went on. Slag droplets moved continuously toward the narrow face and a deeper molten steel area of the mold along with the movement of the stream. After $15 \mathrm{~s}$, some of slag droplets already moved into deeper areas and some even moved to the wall position, which was likely to be captured by the solidified shell.

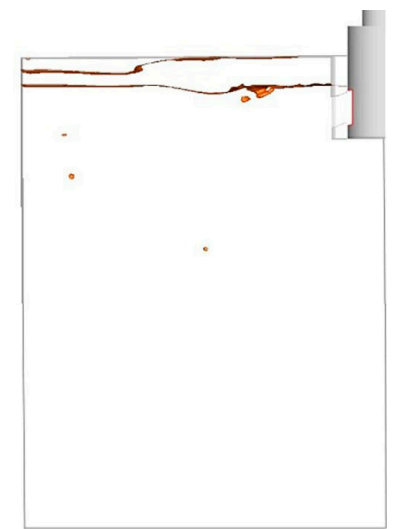

(a)

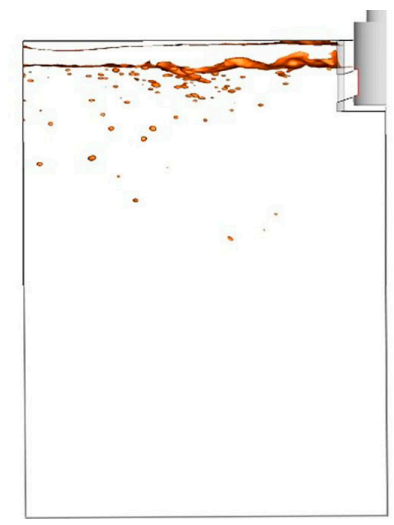

(b)

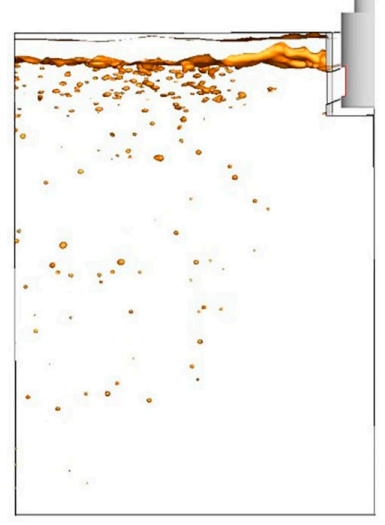

(c)

Figure 8. Slag droplets position at different times: $(\mathbf{a}) t=5 \mathrm{~s} ;(\mathbf{b}) t=10 \mathrm{~s} ;(\mathbf{c}) t=15 \mathrm{~s}$.

To explain the slag droplet entrapment in detail, we selected several cross sections along the longitudinal direction in the mold. Based on the simulation results, we defined the slag entrapment ratio (SER) in each cross section as follows:

$$
\varphi_{\text {slag }}=\frac{S_{\text {slag }}}{S_{\text {slag }}+S_{\text {steel }}} \times 100 \%
$$

Here, $S_{\text {slag }}$ stands for the slag phase volume fraction in each plane calculated by integral and $S_{\text {steel }}$ is the liquid steel phase volume fraction each plane calculated by integral. So, we can obtain the $\varphi_{\text {slag }}$ as Equation (14). Then, SER in the longitudinal was obtained, as shown in Figure 9.

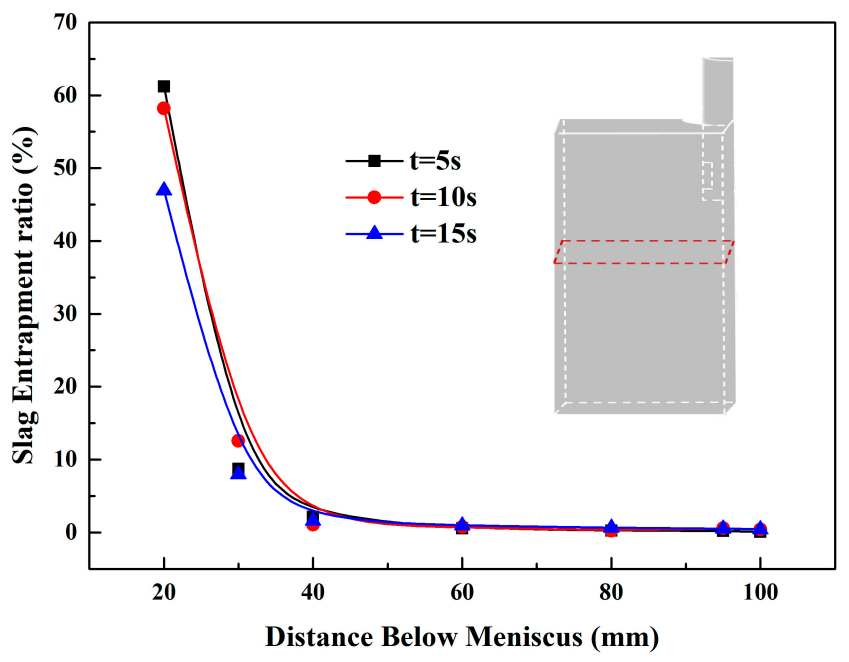

Figure 9. Slag entrapment ratio in each cross section. 
It could be seen that, as time goes on, the area with a high slag entrainment ratio moves down gradually. The slag entrainment ratio below a meniscus of $0.02 \mathrm{~m}$ is the largest $(61.23 \%$ at $\mathrm{t}=5 \mathrm{~s})$, because it is the most drastic area of slag entrapment near the steel slag interface in mold. Then, the slag entrainment ratio begins to decrease after $15 \mathrm{~s}$. This is caused by the slag droplets moving down with the swirling flow. At the same time, the phenomenon of slag entrapment reduces as the depth deepens. The slag droplets in the lower region were mainly derived from those from the upper region with the fluid flow to these areas. All the results reflected that location and the downward movement of the slag droplet. When slag droplets moved to the area $0.1 \mathrm{~m}$ below the meniscus, the largest SER is $0.44 \%$ at $t=15 \mathrm{~s}$. Thus, the value of SER is not high at any time which is consistent with reality.

\subsection{Effect of Oil Used on the Water Modelling Experiments}

Based on an analysis of Section 2.2, the density ratio of water to oil should be consistent with the density of molten steel to slag phase according to the Buckingham $\pi$ theory. To satisfy the similarity of corresponding parameters in the theorem between water modelling and numerical simulation, the type of oil used in water modelling is crucial. To date, there is no clear standard to determine what kind of oil should be used in a water modelling experiment, so we studied the effects of oil used in the water model.

Further to the density ratio, the surface tension of the oil used in water modelling is also an important factor for determining slag entrapment in the continuous casting process. Silicon oil and vegetable oil were studied by other researchers [23-27]. To find out the effects of oil on water modelling experiments, a relation curve was drawn between surface tension of different oils and scale factor as calculated by Equation (13), as shown in Figure 10.

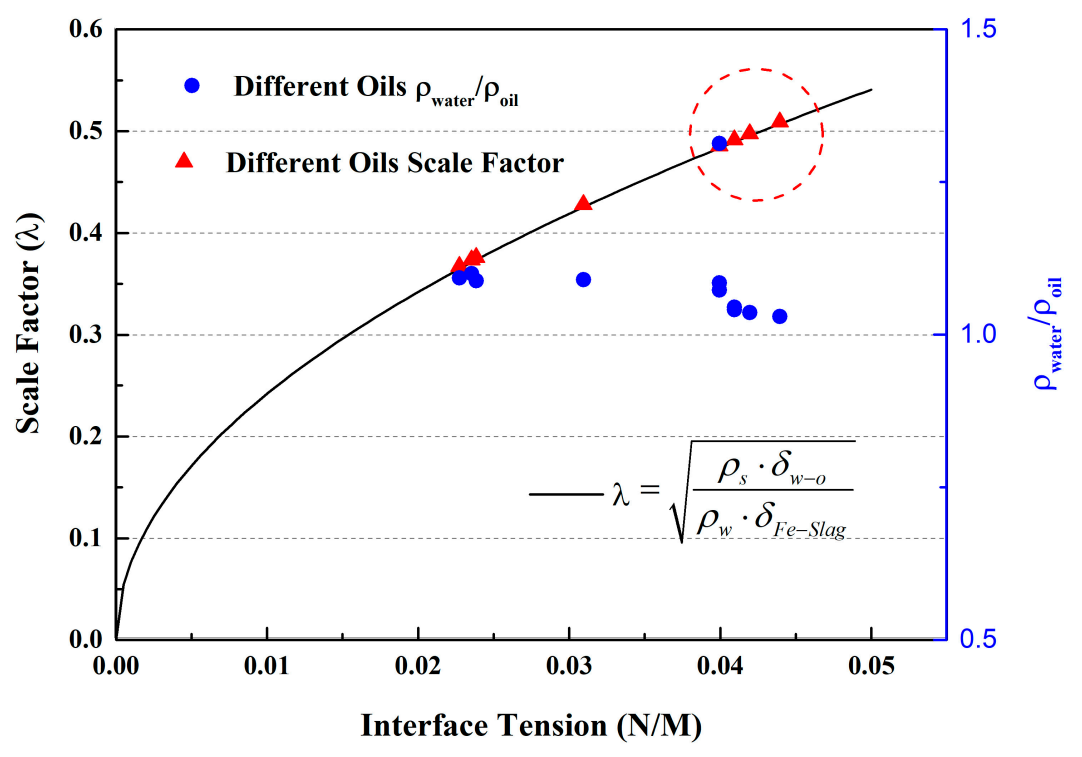

Figure 10. Relations between surface tension of different oil and scale factor.

By observation, it can be found that scale factor increases gradually with the increase of interfacial tension between oil and water. Thus, the scale factor corresponds according to the oil media chosen used in the water modelling experiment. In any case, we should take the density and viscosity of oil into consideration based on our results deduced from Buckingham $\pi$ theory. For the continuous casting mold, the density ratio $\left(\rho_{\text {steel }} / \rho_{\text {slag }}\right)$ was about 2.1 2.5. According to the parameters in Table 2, the density ratio $\rho_{\text {water }} / \rho_{\text {oil }}$ of the liquid-liquid systems varied from 1.0 to 1.3 , which is far more different than the value of 2.5 for steel-slag systems. No literature to date on water modelling of continuous casting molds uses any oil remotely near the ideal value of 2.5. Finding the optimum oil (satisfied with density ratio to water 2.5 , while also being non-toxic and non-volatile) used in water modelling needs further investigation. 
Table 2. Properties of different oils [15,27].

\begin{tabular}{cccc}
\hline Oil & Density $\left(\mathbf{k g} / \mathbf{m}^{\mathbf{3}}\right)$ & Interface Tension $\mathbf{( N / \mathbf { m } )}$ & Density Ratio $\left(\rho_{\text {water }} / \rho_{\text {oil }}\right)$ \\
\hline Silicon oil AK 0.65 & 760 & 0.04 & 1.313 \\
Silicon oil AK5 & 920 & 0.04 & 1.085 \\
Silicon oil AK10 & 930 & 0.04 & 1.073 \\
Silicon oil AK35 & 955 & 0.041 & 1.045 \\
Silicon oil AK50 & 960 & 0.041 & 1.040 \\
Silicon oil AK100 & 963 & 0.042 & 1.036 \\
Silicon oil AK200 & 966 & 0.044 & 1.033 \\
Silicon oil AK500 & 969 & 0.044 & 1.030 \\
Peanut oil & 916 & 0.031 & 1.090 \\
\hline
\end{tabular}

It could be seen from the table that oils in the red circle are the relatively good choices, because the scale factor is about 0.5 and that is convenient for making a water model according to the Equation (13). At the same time, the density ratio of the oil used (silicon oil AK 0.65) in the experiment was the closest one compared with other oils in the Table 2. Thus, it is a better choice to use silicon oil AK 0.65 to simulate the slag phase in the water modelling experiment. This could be used as a reference for how to determine $\lambda$ and oil used in water modelling experiment for slag entrapment in molds.

\subsection{Model Validation}

We compared the results of the water modelling with the numerical simulation results, as shown in Figure 11.

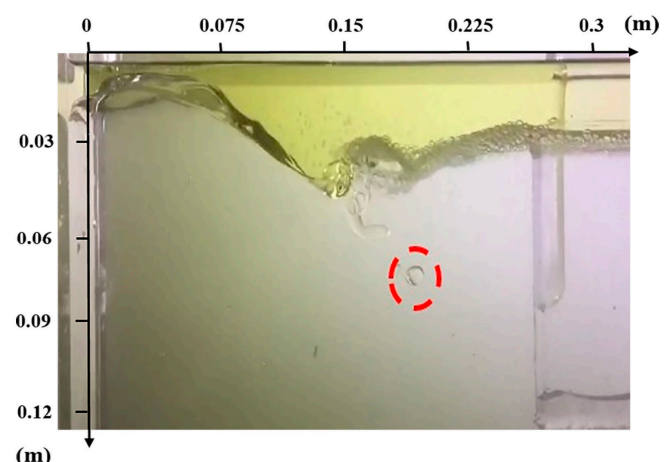

(m)

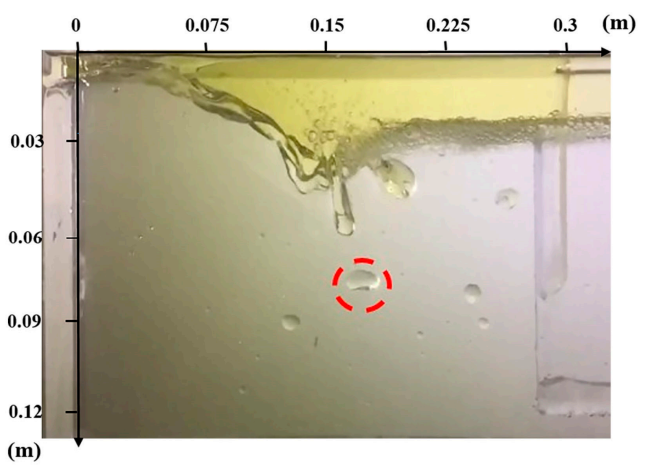

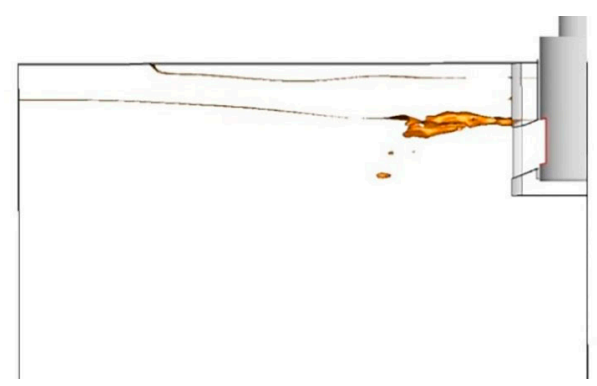

(a)

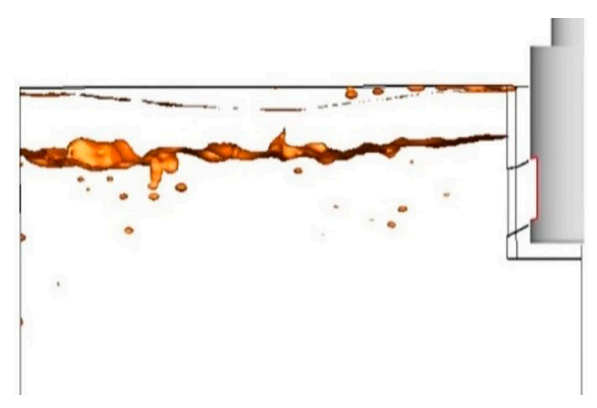

(b)

Figure 11. Comparison of water simulation experiments and numerical results: $(\mathbf{a}) t=5 \mathrm{~s} ;(\mathbf{b}) t=10 \mathrm{~s}$.

We could find that the water modelling results are in good agreement with the numerical simulation results. The coincidence between the water modelling results and the simulation results is high, no matter the position of slag entrainment or the shape and size of slag droplets being involved 
into molten steel. Therefore, the results of numerical simulation can provide us with an effective way of better understanding the occurrence of slag entrapment in a continuous casting process.

To further understand where slag droplets are likely to appear in molds, we draw the velocity curves of different lines at several locations, as shown in Figure 12. From Figure 12a, velocity can be seen to decrease with increasing distance from the SEN port. Along the center line of the nozzle port, the velocity decreased first then began to fluctuate due to the upper circle flow and turbulence. The velocity curve increases with the distance away from the nozzle. Therefore, the slag droplets in the red circle marked in Figure 11a,b both are near the area of the cross section of port center line and away from the SEN $(0.1 \mathrm{~m})$. As the velocity peak appears $(2.0 \mathrm{~m} / \mathrm{s})$, slag droplets are more likely to be entrapped in this area.

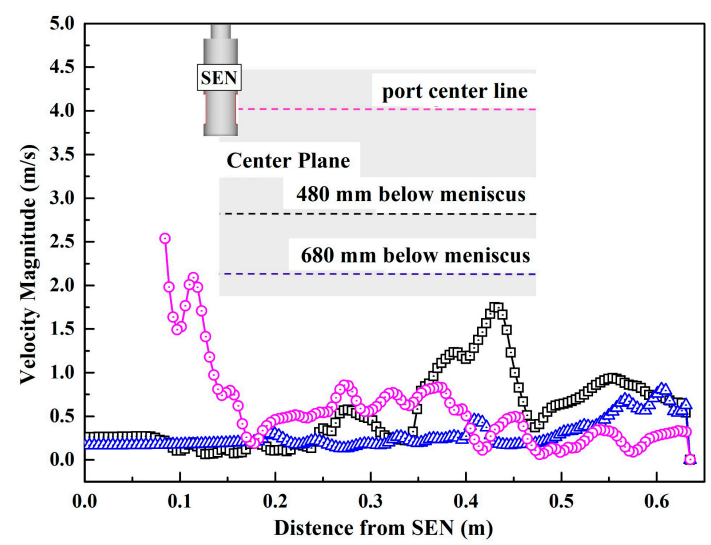

(a)

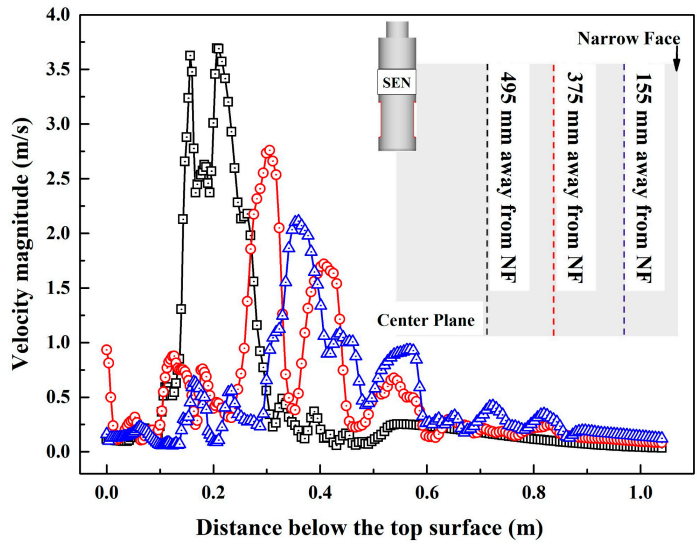

(b)

Figure 12. Velocity distribution of different lines at several locations: (a) horizontal variations; (b) vertical variations.

From Figure 12b, it could be seen that the farther the distance is, the farther the velocity peak appears. At the same time, the maximum velocity decreases with the increase of distance. Thus, these velocity distributions could tell us which areas we should focus on.

\section{Conclusions}

In this paper, the optimum submerged depth and casting speed in a $150 \times 1270 \mathrm{~mm}$ slab continuous casting process were studied by numerical simulation. Then, the slag entrapment behavior in a continuous casting mold was validated by using numerical calculation and water modelling methods. The following conclusions can be drawn from this work:

1. The optimum scheme is SEN submerged depth is $90 \mathrm{~mm}$ and casting speed $1.6 \mathrm{~m} / \mathrm{min}$. The maximum surface velocity of the optimum scheme is the smallest $(0.335 \mathrm{~m} / \mathrm{s})$, which is reduced by $19.1 \%, 11.4 \%$ and $8.3 \%$, respectively, compared with the other three conditions.

2. A new dimensionless parameter, the slag entrapment ratio (SER), was defined to explain the mixing of slag phase in each cross-plane. After $15 \mathrm{~s}$, the maximum SER $(0.44 \%)$ appeared at the position of $0.1 \mathrm{~m}$ below the meniscus.

3. The dimensionless parameter density ratio was found to be an important factor. Furthermore, the density ratio of oil used (silicon oil AK 0.65 ) in the water modelling experiment to water is closer to the density ratio of slag and steel compared with other common oils.

4. The water modelling results were in good agreement with the numerical simulation results and the slag droplets observed in the experiment were found to be more likely to be entrapped in the area where the SER value is large. 
Author Contributions: Conceptualization, S.Y.; data curation, F.W.; investigation, J.L.; writing—original draft, Y.W. Funding: This research was funded by National Natural Science Foundation of China, grant number 51574190 and 51734003 .

Conflicts of Interest: The authors declare no conflicts of interest.

\section{References}

1. Svensson, J.K.S.; Memarpour, A.; Brabie, V.; Jönsson, P.G. Studies of the decarburisation phenomena during preheating of submerged entry nozzles (SEN) in continuous casting processes. Ironmaking Steelmaking 2017, 44, 108-116. [CrossRef]

2. Zhang, L.; Yang, S.; Cai, K.K.; Li, J.; Wan, X.; Thomas, B.G. Investigation of fluid flow and steel cleanliness in the continuous casting strand. Metall. Mater. Trans. B 2007, 38, 63-83. [CrossRef]

3. Sanchez, P.R.; Díaz, C.M.; Olivares, X.O.; Palafox, R.J. A physical model for the two-phase flow in a continuous casting mold. ISIJ Int. 2003, 43, 637-646. [CrossRef]

4. Yuan, Q.; Vanka, S.P.; Thomas, B.G.; Sivaramakrishnan, S. Computational and experimental study of turbulent flow in a 0.4-scale water model of a continuous steel caster. Metall. Mater. Trans. B 2004, 35, 967-982. [CrossRef]

5. Lu, Q.; Yang, R.; Wang, X.; Zhang, J.; Wang, W. Water modeling of mold powder entrapment in slab continuous casting mold. Int. J. Miner. Metall. Mater. 2007, 14, 399-404. [CrossRef]

6. He, Q. Observations of vortex formation in the mould of a continuous slab caster. ISIJ Int. 1993, 33, 343-345. [CrossRef]

7. Solhed, H.; Jonsson, L. An investigation of slag floatation and entrapment in a continuous-casting tundish using fluid-flow simulations, sampling and physical metallurgy. Scand. J. Metall. 2003, 32, 15-32. [CrossRef]

8. Hibbeler, L.C.; Thomas, B.G. Mold slag entrainment mechanisms in continuous casting molds. AISE Steel Technol. 2013, 10, 121-136.

9. Iguchi, M.; Yoshida, J.; Shimizu, T.; Mizuno, Y. Model study on the entrapment of mold powder into molten steel. ISIJ Int. 2000, 40, 685-691. [CrossRef]

10. Helmholtz, H.L.F. Über discontinuirliche Flüssigkeits-Bewegungen. Über die Erhaltung der Kraft 1868, 23, 215-228.

11. Ippen, A.T. Review: L. M. Milne-Thomson, Theoretical Hydrodynamics. Bull. Am. Math. Soc. 1941, 47, 352-353. [CrossRef]

12. Savolainen, J.; Fabritius, T.; Mattila, O. Effect of fluid physical properties on the emulsification. ISIJ Int. 2009, 49, 29-36. [CrossRef]

13. Rallison, J.M. The deformation of small viscous drops and bubbles in shear flows. Annu. Rev. Fluid Mech. 1984, 16, 45-66. [CrossRef]

14. Barthes-Biesel, D.; Acrivos, A. Deformation and burst of a liquid droplet freely suspended in a linear shear field. J. Fluid Mech. 1973, 61, 1-22. [CrossRef]

15. René, H.; Rüdiger, S.; Heller, H.P.; Scheller, P.R. Model investigations on the stability of the steel-slag interface in continuous-casting process. Metall. Mater. Trans. B 2013, 44, 80-90.

16. De Bruijn, R.A. Tipstreaming of drops in simple shear flows. Chem. Eng. Sci. 1993, 48, 277-284. [CrossRef]

17. Cristini, V.; Tan, Y.C. Theory and numerical simulation of droplet dynamics in complex flows-A review. Lab Chip 2004, 4, 257-264. [CrossRef]

18. Christopher, G.F.; Anna, S.L. Microfluidic methods for generating continuous droplet streams. J. Phys. D Appl. Phys. 2007, 40, R319. [CrossRef]

19. Bentley, B.J.; Leal, L.G. An experimental investigation of drop deformation and breakup in steady, two-dimensional linear flows. J. Fluid Mech. 1986, 167, 241-283. [CrossRef]

20. James, A.J.; Lowengrub, J. A surfactant-conserving volume-of-fluid method for interfacial flows with insoluble surfactant. J. Comput. Phys. 2004, 201, 685-722. [CrossRef]

21. Zhou, C.; Yue, P.; Feng, J.J. Formation of simple and compound drops in microfluidic devices. Phys. Fluids 2006, 18, 092105. [CrossRef]

22. Stone, H.A.; Stroock, A.D.; Ajdari, A. Engineering flows in small devices: microfluidics toward a lab-on-a-chip. Annu. Rev. Fluid Mech. 2004, 36, 381-411. [CrossRef] 
23. Melo-Espinosa, E.A.; Sánchez-Borroto, Y.; Errasti, M.; Piloto-Rodríguez, R.; Sierens, R.; Roger-Riba, J.; Christopher-Hansen, A. Surface tension prediction of vegetable oils using artificial neural networks and multiple linear regression. Energy Procedia 2014, 57, 886-895. [CrossRef]

24. Siddiqui, N.; Ahmad, A. A study on viscosity, surface tension and volume flow rate of some edible and medicinal oils. Int. J. Sci. Environ. Technol. 2013, 2, 1318-1326.

25. Sahasrabudhe, S.N.; Rodriguez-Martinez, V.; O'Meara, M.; Farkas, B.E. Density, viscosity, and surface tension of five vegetable oils at elevated temperatures: Measurement and modeling. Int. J. Food Prop. 2017, 20, 1965-1981. [CrossRef]

26. Fisher, L.R.; Mitchell, E.E.; Parker, N.S. Interfacial tensions of commercial vegetable oils with water. J. Food Sci. 1985, 50, 1201-1202. [CrossRef]

27. Gaonkar, A.G. Interfacial tensions of vegetable oil/water systems: Effect of oil purification. J. Am. Oil Chem. Soc. 1989, 66, 1090-1092. [CrossRef]

(C) 2019 by the authors. Licensee MDPI, Basel, Switzerland. This article is an open access article distributed under the terms and conditions of the Creative Commons Attribution (CC BY) license (http://creativecommons.org/licenses/by/4.0/). 